\title{
JUNIOR NATURALISTS
}

\section{YOUTH COLUMN}

Yes! a column just for you. This is a spot for you to air your concerns, questions or writings, so feel free to contact me, your youth director. There will be a column in future Blue Jay magazines.

\section{Winter}

In winter sometimes it feels like the world outside should be frozen and still, but in fact there's a lot of activity to discover if we become more aware.

Use all your senses when you go out and you will find signs of wildlife, and may be able to tell what they've been doing. Lets explore ...

What is one of the first things you do when you get up in the morning? Well animals eat, too, and their kitchen is all around you. Look for gnawings * on wood or signs of browse $^{*}$, which is for instance a chewed off twig. Maybe there are signs of pecking * in the bark and wood of some trees. If a carnivore (meat eater) has been feeding you may see fur, * feathers * or a bit of blood* left over. There's different food for everyone and all eat.

What's one of the other things you do first thing in the morning? Well, animals need to do that, too, and just by looking at it we can learn what animals are in the area and what they have found to eat. For instance the coyote * scat $^{*}$ may have some fur in it from a past meal. A rabbit* or hare * pellet* will have left over bits of plants in it. And, I'm sure you're all familiar with bird droppings*, hopefully you find them somewhere other than your sleeve!

There is another sign of birds that's very interesting to find. Birds of prey, like owls and hawks can't digest all they swallow, so it forms in. to a lump, they cough it up and spit it out. This lump is called a pellet. Can you guess what might be in it? (If you guessed bones, ${ }^{\star}$ feathers ${ }^{*}$ or fur, ${ }^{*}$ good for you!)

Animals need a place to sleep - a weasel's ${ }^{*}$ den * for instance could be a crevice by the root of a tree, a rabbit's den may be under a layer of shrubs or fallen tree branches. A hole in the side of a snowbank may be from a grouse* who dove into the snow for warmth.

Of course along with all the above signs of wildlife comes the most commonly seen sign; foot or wing prints, the animal's tracks ${ }^{*}$. Was the animal big or little? are its feet different sizes (like a rabbit's)? was it running? Maybe the tracks lead to a little hole in the snow. Like the grouse, a mouse* or a weasel will often dive into the snow.

There's a lot to explore isn't there? But wait a minute, there's even more! What about your other senses? So far we've only explored some of the things you can see. What animal might you be able to smell? or who is calling *, or singing *, or tapping * on wood, or whooshing * through the trees, or snapping * twigs, or crunching ${ }^{\star} ?$... 
If you use all your senses to explore, you'll experience and notice things that you can be excited to tell your friends about. In fact, I'd be interested in your stories, too. Please write and tell me why you care about wildlife, and about your sightings or experiences.

There is an organization called the Canadian Wildlife Service who studies wildlife and the places they live. In the last Saskatchewan Natural
History Society Newsletter there was a special inclusion describing cutbacks to the Canadian Wildlife Service. They need to know that a lot of people care about wildlife, people like you.

So, if you like seeing wildlife and do care, send a letter telling me about it. It'll be printed in the next Blue Jay. - Heidi Sutherland, 901 - 2020 Bellevue Avenue, West Vancouver, British Columbia. V7V 1B8

* The words marked with the * are used in the following puzzle:

Look for the following hidden words. They may be found horizontally, vertically, or diagonally, either forwards or backwards. Circle the word when you have found it and check it off. These are some of the animals you may find in the winter, also some of their signs. Good luck!

GROUSE

PORCUPINE

WOODPECKER

MOUSE

SPARROW

PLLE MSREHTAEFZZ

EWDEERTAZZSKUNK

L E Z B R OWS E Z Z E Z Y Z

L A Z Z Y K T R A C K S C A T

E S U OR G ZVZ Y I UZZZ

T E CRUNCH I N GOWLR

E L E A Z Z Z G Z N M T S

$N S E B L Z G I G N I W A N K$

I $P D B Z L N Z Z Z H Z P A C$

$P A A|B G| Z Z A C Z P P E$

URKTOLPNRZNF I P P

C RCZNZOEGEUZNI D

ROI Z E Z R O RR Z GNO

OWHZSZDZDZCZZGO

$P E C K I N G N I H S O O H W$
CHICKADEE

HARE

RABBIT

COYOTE

DEER

WEASEL

OWL

HAWK

SKUNK

SINGING

CALLING

TAPPING

WHOOSHING

SNAPPING

CRUNCHING

PECKING

DROPPINGS

SMELL

KNAWING

PELLET

SCAT

DEN

FUR

FEATHERS

BONES

BLOOD

TRACKS

BROWSE 